\title{
Unbiased Selectivity Coefficients Obtained for the Pulsed Chronopotentiometric Polymeric Membrane Ion Sensors
}

\author{
Hasini Perera, Alexey Shvarev*. \\ Department of Chemistry, Oregon State University, 153 Gilbert Hall, Corvallis, OR, 97331-4003. \\ alexey.shvarev@oregonstate.edu
}

\begin{abstract}
Reagents.
High molecular weight poly(vinyl chloride)(PVC), bis(2ethylhexyl) sebacate (DOS), valinomycin, tetradodecylammonium tetrakis-(4-chlorophenyl)borate (ETH 500), tetrahydrofuran (THF), and all salts were purchased from Sigma - Aldrich (Milwaukee, WI). Aqueous solutions were prepared by dissolving the appropriate salts in deionized water $(18.2 \mathrm{M} \Omega \mathrm{cm})$.
\end{abstract}

\section{Pulsed Galvanostatic Electrodes}

Pulsed galvanostatic electrode membrane contained valinomycin $1.1 \mathrm{wt} \%\left(9.9 \mathrm{mmol} \mathrm{kg}^{-1}\right)$, tetradodecylammonium tetrakis-(4-chlorophenyl)borate $8.3 \quad \mathrm{wt} \% \quad\left(72.3 \quad \mathrm{mmol} \quad \mathrm{kg}^{-1}\right)$, poly(vinyl chloride) $30.2 \mathrm{wt} \%$, bis(2-ethylhexyl) sebacate (DOS) $60.4 \mathrm{wt} \%$ totaling $140 \mathrm{mg}$. The membrane components were dissolved in $1.5 \mathrm{ml}$ of tetrahydrofuran (THF). By casting this solution into a plastic ring of $22 \mathrm{~mm}$ diameter, membrane of ca. $200 \mu \mathrm{m}$ thicknesses were obtained.

The ion-selective membranes were cut with a cork bore (6.6 $\mathrm{mm}$ in diameter) from the parent membrane and incorporated into the Philips electrode body (IS-561, Glasbläserei Möller, Zurich, Switzerland) with the $\mathrm{Ag} / \mathrm{AgCl}$ internal reference electrode. The inner filling solution contained either $0.01 \mathrm{M} \mathrm{NaCl}$ or $0.01 \mathrm{M} \mathrm{KCl}$. The exposed membrane area was $0.08 \mathrm{~cm}^{2}$. Electrodes were conditioned overnight in a solution identical to the inner filling solution.

\section{Chronopotentiometric measurements.}

A conventional three-electrode cell was used for chronopotentiometric measurements. The membrane electrode was connected as a working electrode. A high surface area platinum wire cage was used as a counter electrode. The reference electrode was a double junction $\mathrm{Ag} / \mathrm{AgCl}$ electrode with saturated $\mathrm{KCl}$ as the inner solution and $1 \mathrm{M} \mathrm{LiOAc}$ as a bridge electrolyte.

A modified AFCBP1 bipotentiostat (Pine Instruments, Grove City, MA) controlled by a PCI-6221 data acquisition board and LabVIEW 7.1 software (National Instruments, Austin, TX) on a PC was used for the measurements. ${ }^{1}$

An uptake current pulse of $1 \mathrm{~s}$ was followed by setting current to zero. Sampled potentials were obtained as the average value during the last $10 \%$ of this zero current pulse. Thus, the potential values did not contain the $i R$ drop. To expel the extracted ions the stripping potential was applied in the potentiostatic mode for $10 \mathrm{~s}$. The background electrolyte was $0.01 \mathrm{M}$ tris- $\mathrm{HCl}$ buffer solution (pH ca. 8.0).

\section{Potentiometric Electrodes}

The ion-selective electrode membranes were cast by dissolving valinomycin $1.19 \mathrm{wt} \%\left(10.62 \mathrm{mmol} \mathrm{kg}{ }^{-1}\right)$, sodium tetrakis[3,5bis(trifluoromethyl)phenyl]borate $0.56 \mathrm{wt} \%\left(6.338 \mathrm{mmol} \mathrm{kg}^{-1}\right)$, poly(vinyl chloride) $32.77 \mathrm{wt} \%$, and bis(2-ethylhexyl) sebacate (DOS) $65.48 \mathrm{wt} \%$ totaling $140 \mathrm{mg}$ in $1.5 \mathrm{ml} \mathrm{THF}$ and pouring it into a plastic ring $(22 \mathrm{~mm}$ id) affixed onto a microscopic glass slide.

For each electrode, a $6.6 \mathrm{~mm}$ diameter disk was cut with a cork borer from the parent membrane and incorporated into a Phillips electrode body (IS-561, Glasblàserei Moller, Zurich, Switzerland). Either $0.01 \mathrm{M} \mathrm{NaCl}$ or $0.01 \mathrm{M} \mathrm{KCl}$ served as the internal filling solution for the assembled electrodes. The electrodes were conditioned in a solution identical to the inner filling solution overnight before measurement.

\section{Potentiometric measurements}

All membrane electrode potential measurements were performed at laboratory ambient temperature vs. a double junction $\mathrm{Ag} / \mathrm{AgCl}$ reference electrode (Ingold, Wilmington, MA) in a galvanic cell of the type:

$\mathrm{Ag} / \mathrm{AgCl} / \mathrm{KCl} / 1 \mathrm{M} \mathrm{LiOAc} / /$ sample // membrane // inner filling solution / $\mathrm{AgCl} / \mathrm{Ag}$

Potentials were measured in unstirred solutions via a custombuilt potentiometric station, which included several electrometric amplifiers (AD820, Analog Devices) connected to the 24-bit 8channel data acquisition board NI-4351 controlled by the LabVIEW software (National Instruments, Austin, TX).

To minimize the noise, final e.m.f. values were calculated as the mean of the individual data points taken over $60 \mathrm{sec}$. measurements.

(1) Makarychev-Mikhailov, S.; Shvarev, A.; Bakker, E. J. Am. Chem. Soc. 2004, 126, 10548-105 
